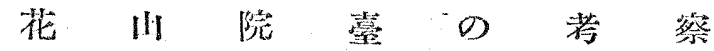

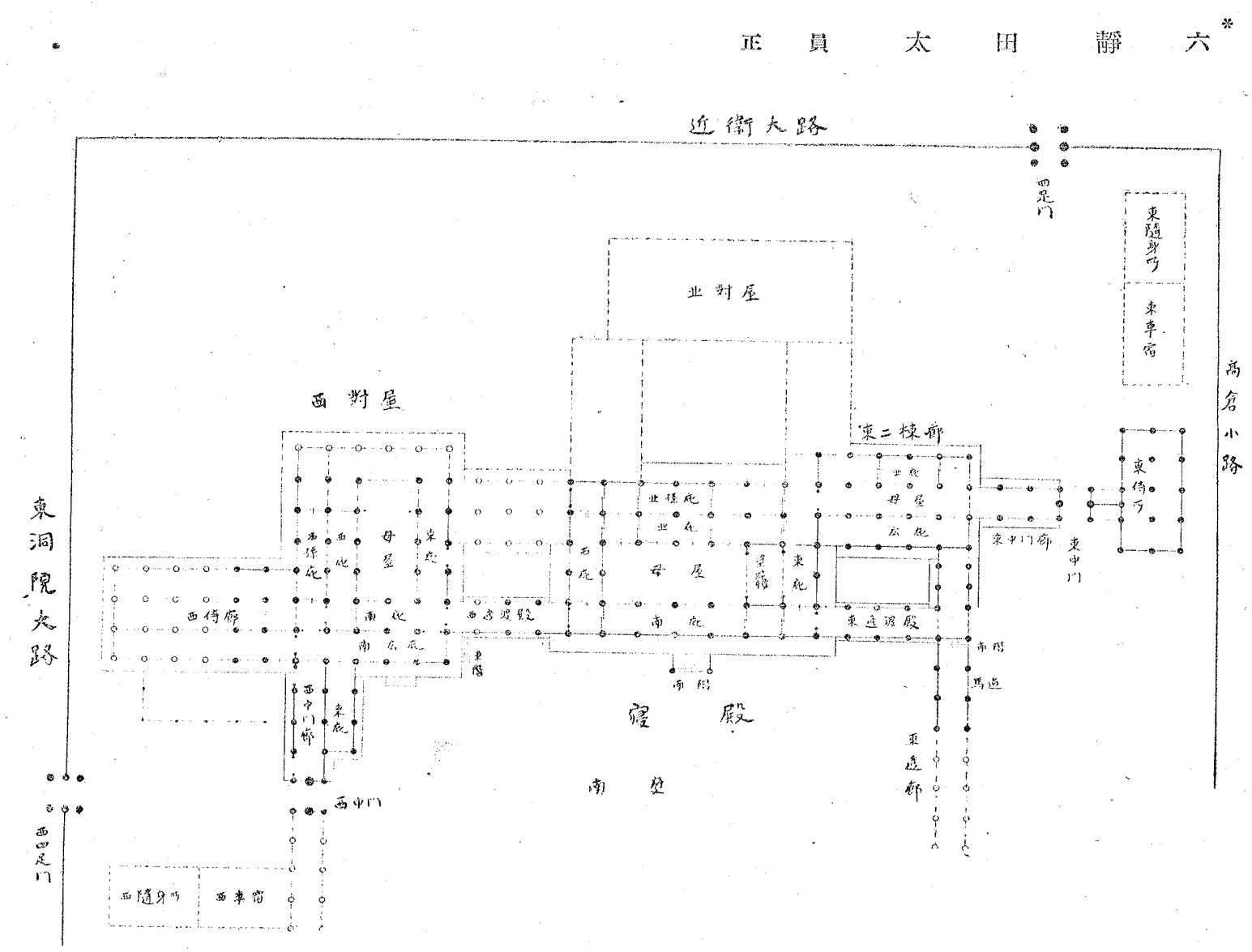

第 1 圆 壮山院第得原 岡

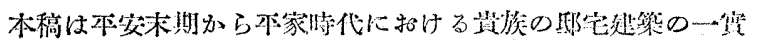
例として花川院籍の沿革や规模等につき述心たものである。拸

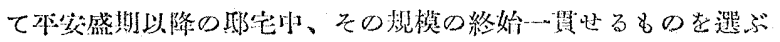

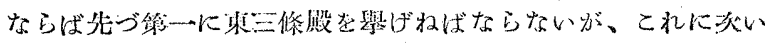

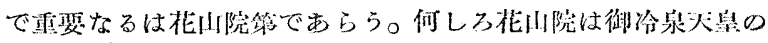

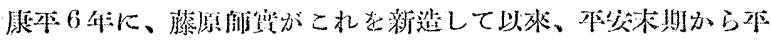

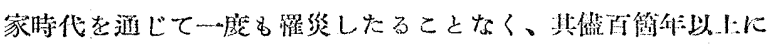

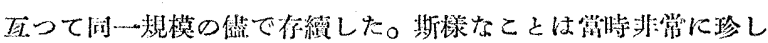

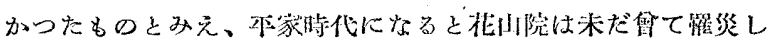
たととのない家として非算に住名になった。即古有名になった

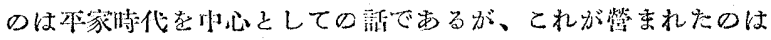

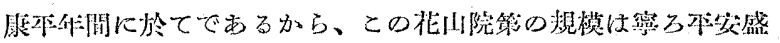

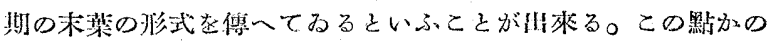

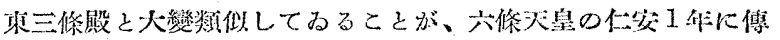

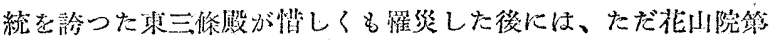

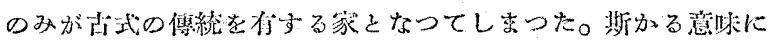

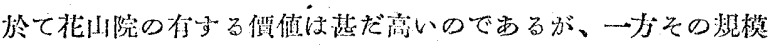
も亦大いに泩目するに值す尚。

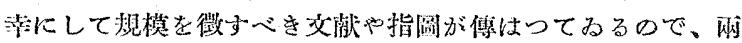

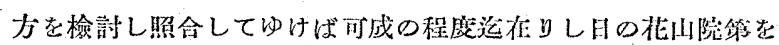

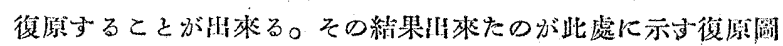

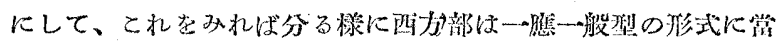

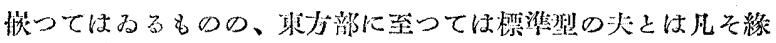

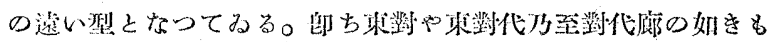

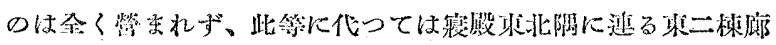

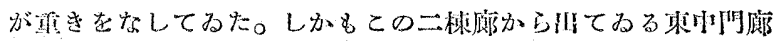

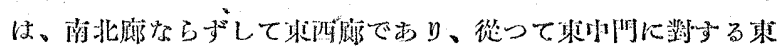

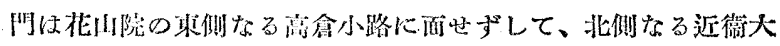

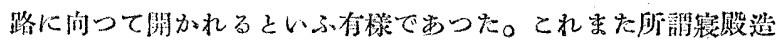
に和けるるは大分相连与るが、想ふにてれは院の臬面が幅の猍

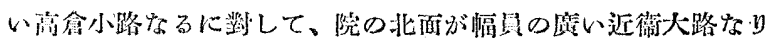

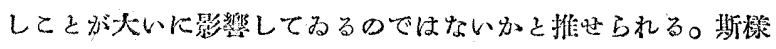

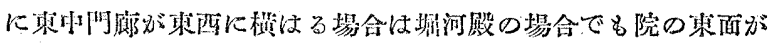
油小路なるに踋して、北面は二條大路であつた。

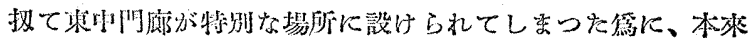

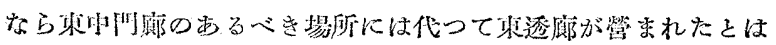

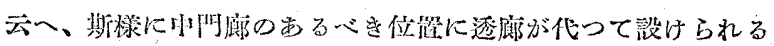

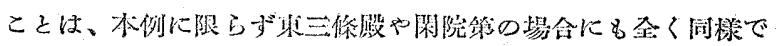

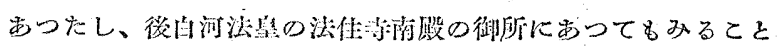

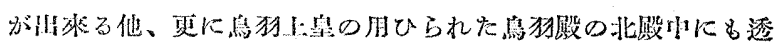

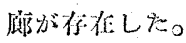

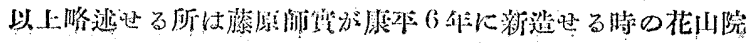

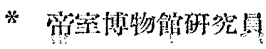




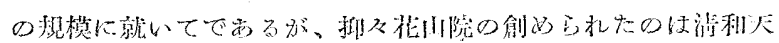

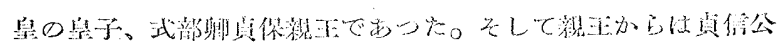

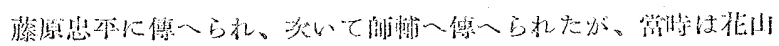

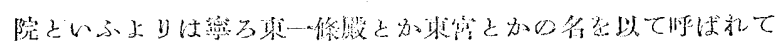

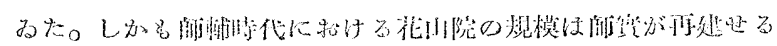

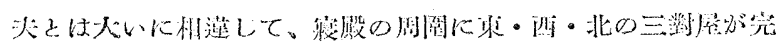

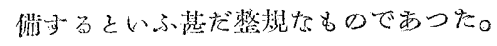

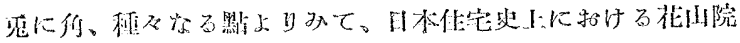

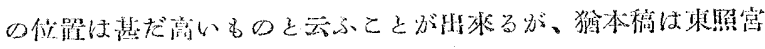

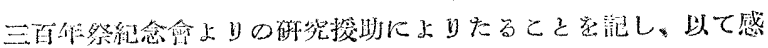

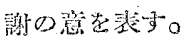

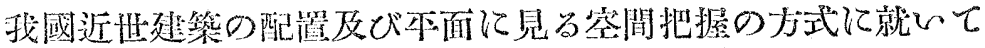

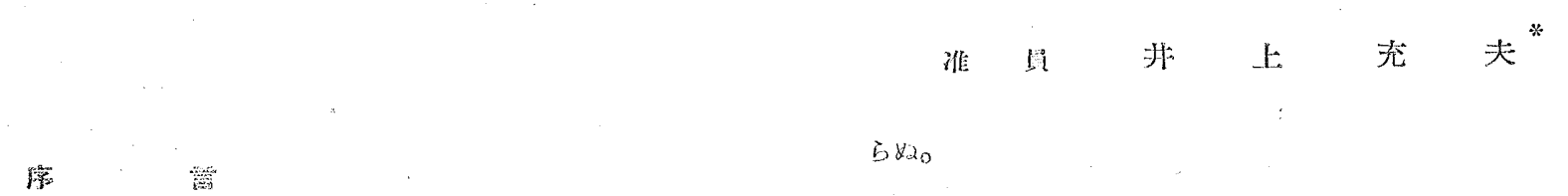

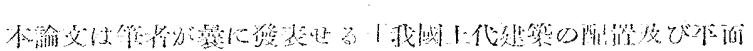

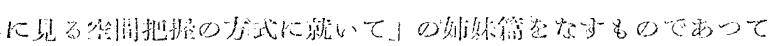

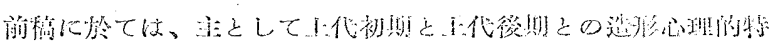

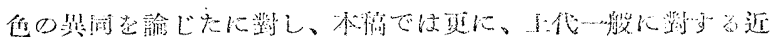

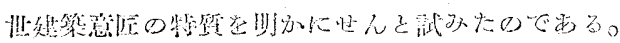

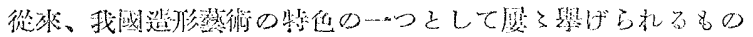

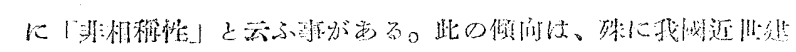

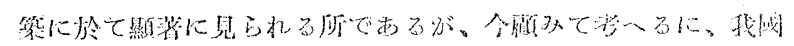

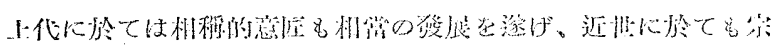

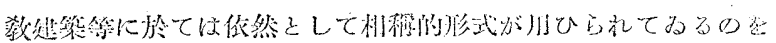

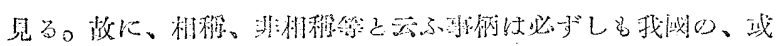

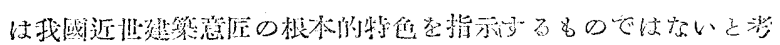

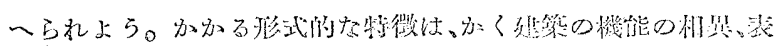

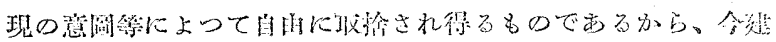

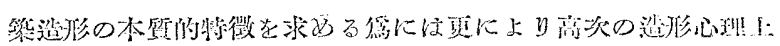

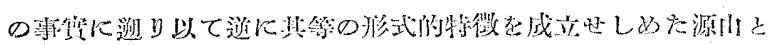

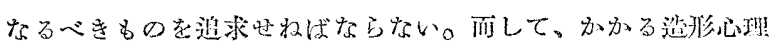

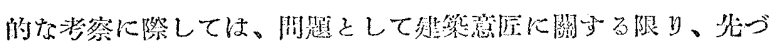

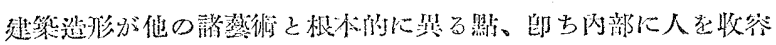

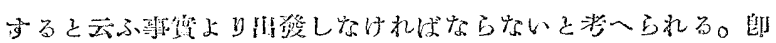

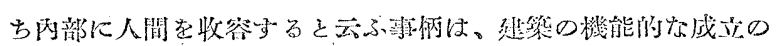

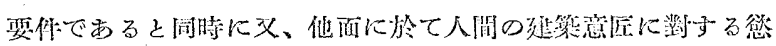

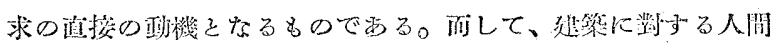

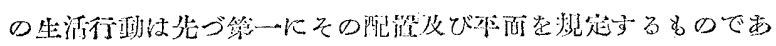

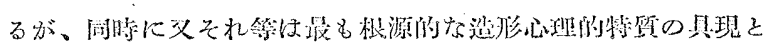
なると考一ら机る。

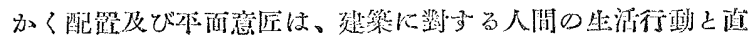

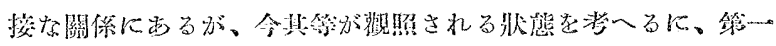

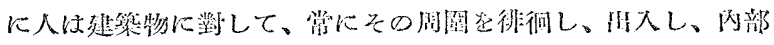

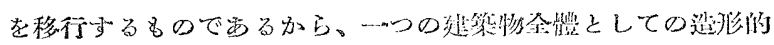

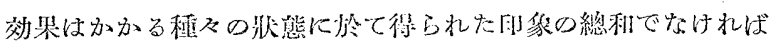

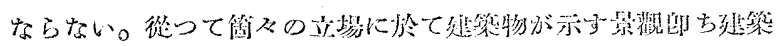

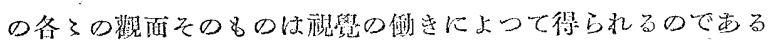

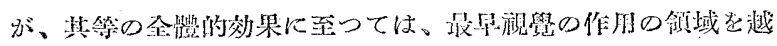

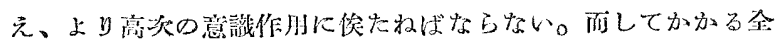

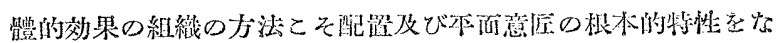

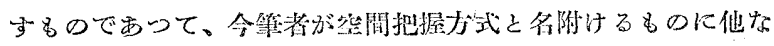

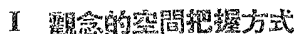

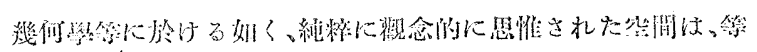

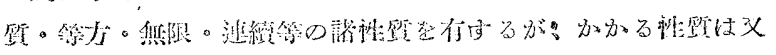

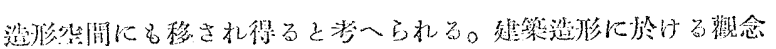

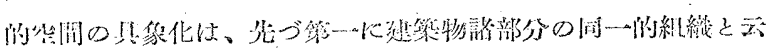

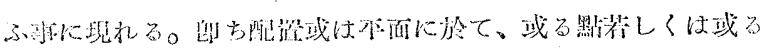

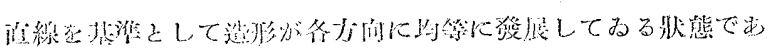

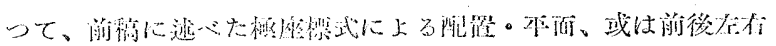

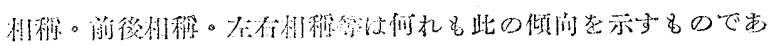

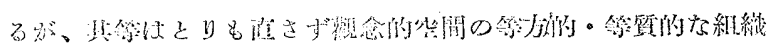

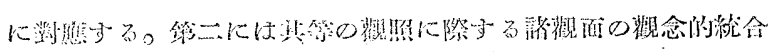

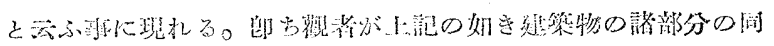

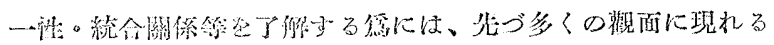

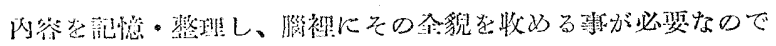

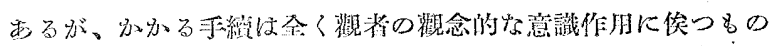

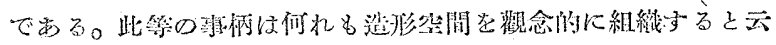

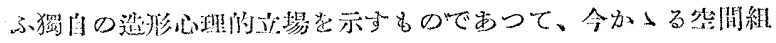

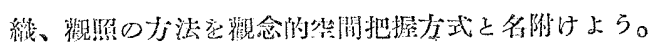

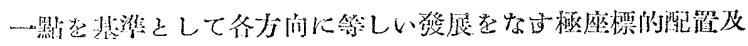

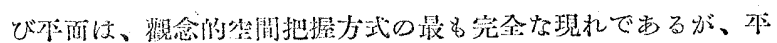

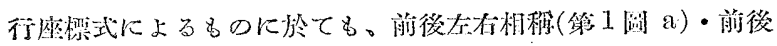

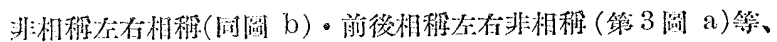

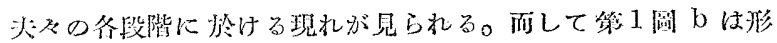

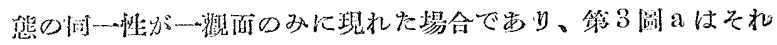

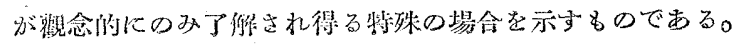

a

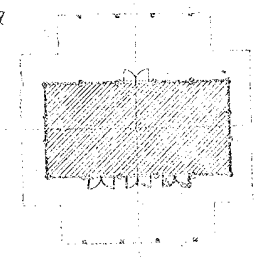

e

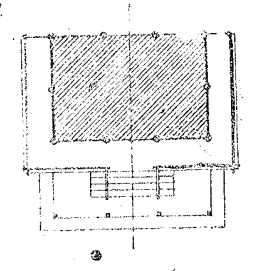

第 1 圖

\section{1 行動的故間把偓方式}

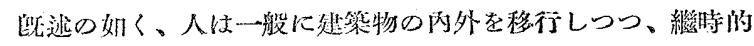

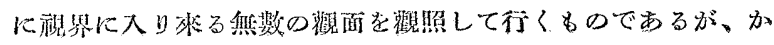

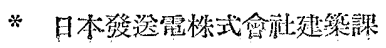

